\title{
Entre Voltas e (Re)voltas: um Estudo sobre Mães que abandonam a Carreira Profissional
}

\author{
Thassia Souza Emidio ${ }^{1}$ \\ Matheus Fernandes de Castro ${ }^{1}$ \\ ${ }^{1}$ Universidade Estadual Paulista Júlio de Mesquita Filho, ${ }^{1}$ Universidade Estadual Paulista Júlio de Mesquita Filho, \\ Assis, SP, Brasil. \\ Assis, SP, Brasil.
}

Resumo: O presente estudo objetivou compreender o movimento de mulheres que, na atualidade, abandonam suas carreiras para se dedicarem ao cuidado com os filhos, a partir de uma reflexão sobre a relação entre maternidade e trabalho. Este trabalho baseia-se numa pesquisa qualitativa que empregou a entrevista semidirigida como instrumento de coleta de dados. Investigou-se nos relatos dessas mulheres o sentido dessa escolha, que se buscou articular às discussões e reflexões teóricas acerca das transformações históricas da maternidade, do papel da mulher na sociedade e sua relação com o trabalho. Os resultados expressaram que apesar de as mulheres terem formulado diversos sentidos para o abandono da carreira, eles convergem em relação às dificuldades de conciliação entre as exigências profissionais e os padrões estabelecidos sobre a experiência de maternagem. Tais sentidos atribuídos a esse movimento refletem nas discussões apresentadas sobre a idealização da maternidade, como também sobre as dificuldades enfrentadas pelas mulheres na construção de seu lugar na sociedade, no mercado de trabalho e na consolidação de sua carreira.

Palavras-chave: Feminino, Maternidade, Trabalho.

\section{Between Shifts And Uprisings: a Study on Mothers who abandon their Professional Careers}

\begin{abstract}
From a reflection on the motherhood-work relationship, this study aims to understand the movement of women who abandon their careers to dedicate themselves to taking care of their children. This qualitative research used data collected by means of semi-structured interviews conducted with mothers. Based on their reports, the meanings underlying this choice were investigated and articulated with discussions and theoretical reflections on the historical transformations of motherhood, the role of women in society, and their relationship with work. The results show that women abandon their professional careers due to different reasons, all of which converge into the difficulties of reconciling professional demands with patterns of maternal experience. Such meanings reflect the discussions about the idealization of motherhood and the difficulties faced by women in constructing their social place, entering the labor market, and in consolidating their careers.
\end{abstract}

Keywords: Feminine, Maternity, Work.

\section{Entre Vueltas y (Re)vueltas: un Estudio sobre Madres que renuncian a su Carrera Profesional}

Resumen: En este estudio se propone comprender el movimiento de mujeres que en la actualidad renuncian a su carrera para dedicarse al cuidado de sus hijos, a partir de una reflexión sobre la 
relación entre maternidad y trabajo. Este trabajo parte de una investigación cualitativa cuyo instrumento de recopilación de datos fue entrevista semidirigida. Se investigó en los relatos de esas mujeres el sentido de esa elección y se buscó articularla con las discusiones y reflexiones teóricas acerca de las transformaciones históricas de la maternidad, del papel de la mujer en la sociedad y su relación con el trabajo. Los resultados expresaron que las mujeres presentan diversos sentidos para la renuncia a la carrera y que estos convergen a las dificultades de conciliación entre las exigencias profesionales y los patrones establecidos sobre la experiencia de maternaje. Tales sentidos atribuidos a ese movimiento reflejan las discusiones presentadas sobre la idealización de la maternidad, así como sobre las dificultades enfrentadas por las mujeres en la construcción de su lugar en la sociedad, en la inserción en el mercado laboral y en la consolidación de su carrera.

Palabras clave: Femenino, Maternidad, Trabajo.

\section{Introdução}

A atualidade é marcada por um posicionamento plural da mulher frente à maternidade, cenário em que dois fenômenos opostos têm levado pesquisadores à reflexão: o posicionamento de não ter filhos e se dedicar integralmente a seus projetos profissionais e individuais; e a opção de abandonar as carreiras profissionais e se dedicar integralmente ao cuidado com os filhos. Esses dois movimentos distintos apontam para algumas das diversas possibilidades de vivências para o feminino na contemporaneidade.

Barbosa e Rocha-Coutinho (2012) relatam que, ao longo do tempo, a conexão estabelecida pela cultura e pela história social entre as características femininas e a função materna limitou a existência das mulheres. A elas foram atribuídas, como percurso natural, a maternidade e suas atividades correlatas, o que influenciou, inclusive, a instituição do casamento e sua manutenção, e as afastou do mundo dos negócios e da esfera pública. Historicamente, aquelas que se rebelaram foram e continuam sendo percebidas com suspeita, sob a pecha de mulheres incompletas, tristes, solitárias e menos femininas.

A partir do feminismo e da propagação de ideais de liberdade, buscou-se desvencilhar a maternidade da identidade da mulher: foi o início da discussão sobre os laços de opressão que a visão romanceada do ser mãe conferia à vida da mulher (Meyer, 2006). Isso abriu espaço para uma reflexão sobre as implicações sociais e políticas da maternidade, bem como sobre suas ambiguidades, na medida em que sua exaltação ocultava os aspectos mais penosos e impedia a reflexão e a escolha mais consciente. Assim, a partir dessa discussão, tornou-se possível, mesmo que timidamente, uma escolha reflexiva acerca da maternidade.
Badinter (2010) relaciona diretamente essas mudanças à invenção dos métodos contraceptivos. A maternidade, que exigia da mulher dedicação em tempo integral e regulava sua vida sexual, passou a poder ser repensada quanto ao melhor momento para acontecer. Tal possibilidade desvinculou a mulher da obrigação de procriar, estabelecendo um diálogo entre o desejo pela maternidade e outros possíveis desejos femininos.

Segundo Mansur (2003), somente no século XX as mulheres tiveram, de fato, $\mathrm{o}$ acesso à modernidade $\mathrm{e}$ ao rompimento com a identidade unificada, forjada nos últimos séculos: "tempo da modernidade em que se torna possível uma posição de sujeito, indivíduo de corpo inteiro e atriz política, futura cidadã" (Mansur, 2003, p. 31). Concomitantemente, com a globalização do capital, novas mudanças incidiram sobre a família e a sociedade: o trabalho requisitou uma grande reestruturação social devido à alta competitividade e abriu-se espaço para a mulher adentrar, novamente, no mercado de trabalho. Assim, elas puderam ocupar os espaços de trabalhos e ganhar novos poderes exteriores ao lar.

Segundo Rocha-Coutinho (2007), a história do trabalho feminino é constituída por avanços, retrocessos e permanências. Em um primeiro momento, as mulheres foram inseridas no mercado de trabalho, essencialmente por uma necessidade de mão de obra no contexto da Primeira Revolução Industrial (século XVIII) e, posteriormente (final do século XIX e início do século XX), foram retiradas desse espaço por um movimento higienista e pela construção da figura da mãe higiênica, aquela que zela pela saúde da família, retomando, sob novos imperativos, seu espaço construído no ambiente doméstico. 
Expansão industrial e empoderamento feminino marcam uma reinserção significativa da mulher no mercado de trabalho nos anos 1970. Segundo Bruschini (2007), nesse período, as trabalhadoras eram quase exclusivamente mulheres jovens, solteiras e sem filhos; às mães restou uma inserção lenta e gradual, pois demandava uma reorganização do espaço doméstico e da vida familiar. Contudo, é preciso destacar as camadas mais pobres da população nesse processo, pois as mulheres pobres sempre trabalharam em busca do sustento de suas famílias (Losada \& Rocha-Coutinho, 2007).

O fator financeiro também é importante nesse período de reinserção feminina no mercado de trabalho: as dificuldades políticas e econômicas por que passava o Brasil, na década de 1970, levaram a uma queda na qualidade dos serviços públicos básicos e ao consequente empobrecimento de mais famílias, de forma que elas foram obrigadas a buscar novas possibilidades de renda para complementar seu orçamento defasado (Bruschini, 2007). Nesse sentido, a disseminação do discurso do consumo, propagandeado pela mídia, fortalecia o discurso global de uma cidadania pautada sobre ele (Santos, 1987), marcando o trabalho como forma de emancipação financeira. Soma-se a isso o aumento da escolarização da população brasileira, em especial da população feminina, que colaborou para sua transição para o mercado de trabalho e para a consequente transformação da família e da maternidade.

Segundo Sousa e Guedes (2016), essa transformação atingiria diretamente a divisão sexual do trabalho, que foi construída baseada na ideia de que às mulheres cabiam o espaço privado e o trabalho do cuidado, exercido sem remuneração (trabalho reprodutivo), e aos homens, o espaço público e o trabalho remunerado (trabalho produtivo), o que sustenta a ideia do homem provedor. Para Hirata e Kergoat (2007), a divisão sexual do trabalho é fruto de uma divisão social construída na relação entre os sexos, que modula e apoia a sobrevivência da relação direta entre homens e mulheres: continua-se sustentando os pressupostos de que há uma diferença entre o que é trabalho de homem e o que é trabalho de mulher, bem como uma valorização desigual entre o trabalho masculino e feminino, na medida em que o trabalho do homem valeria mais. Contudo, o ingresso das mulheres no mercado de trabalho não trouxe um equilíbrio para as funções exercidas entre os sexos, mas reforçou as desvantagens vividas pelas mulheres, que passam a assumir mais um papel, o da mulher trabalhadora, que compartilha com o homem o sustento do grupo familiar, e que, em sua maioria, permanecem cumprindo sozinhas as atividades do espaço privado. Além disso, as mulheres também não alcançaram a mesma valorização no mercado de trabalho.

Segundo dados do Instituto Brasileiro de Geografia eEstatística (IBGE, 2012), entre 2000 e 2010, o papel da mulher responsável pela família subiu de $22,2 \%$ para $37,3 \%$, ao mesmo tempo que dados da Pesquisa Nacional por Amostra de Domicílios (PNAD) do IBGE apontam que as pessoas da família responsáveis pelo cuidado da casa e dos afazeres doméstico eram $92,25 \%$ mulheres e $51,44 \%$ homens em 2004; e 92,84\% mulheres e 58,36\% homens em 2014, o que evidencia a desigual divisão com relação aos espaços públicos e privados entre mulheres e homens, de modo que as tarefas referentes ao lar ainda permanecem significativamente a cargo das mulheres. Dados da PNAD, em 2016, revelam também que em relação ao rendimento médio mensal do trabalho, entre 2012 e 2016, as mulheres ganharam, em média, $75 \%$ do rendimento dos homens no exercício das mesmas funções, evidência de que a desigualdade entre homens e mulheres permanece no mercado de trabalho.

Essas diferenças também trazem consequências no exercício do trabalho feminino e na relação com as responsabilidades ligadas ao grupo familiar. De acordo com Guedes e Araújo (2011), os dados sobre o trabalho feminino e o trabalho doméstico apontam a desarmonia entre o avanço da inserção da mulher no mercado de trabalho e a "desnaturalização" dos tradicionais papeis femininos, o que leva muitas mulheres a viverem um conflito relacionado às atividades domésticas e ao trabalho.

Hirata (2015) indica que, no contexto atual, a divisão sexual do trabalho pode tomar quatro formas: a de um modelo tradicional, em que as mulheres são cuidadoras e os homens são provedores; o modelo de conciliação, em que as mulheres buscam conciliar a vida profissional com a vida familiar; o modelo de parceria, em que homens e mulheres compartilham as tarefas domésticas e os cuidados com a família; e o modelo da delegação, em que as tarefas domésticas são delegadas a outros profissionais que exercem a função do cuidado com a casa e com os filhos. Segundo a autora, a sociedade 
brasileira congrega os quatro modelos, com a prevalência do segundo - em que mulheres buscam conciliar a vida profissional com a vida familiar -, evidência de que, embora haja uma inserção da mulher no mercado de trabalho e um processo de transformação do papel da mulher na família e no trabalho, as relações entre os gêneros ainda apresentam mudanças pouco significativas, de forma que se mantêm estáveis e sustentam uma condição de desigualdade na divisão sexual do trabalho. Destaca-se que em uma sociedade capitalista de consumo em que o trabalho é alienado, a luta pela emancipação vai muito além da inserção no mercado de trabalho.

Nesse sentido, Rocha-Coutinho (2007) observa que o discurso social, embora tenha agregado a função de trabalhadora à identidade da mulher, mudou muito pouco a definição de ser mulher e continua a atribuir às mulheres todos os encargos com a casa e com a família, de forma que a mulher deve buscar a conciliação entre suas diversas funções. Nesse caminho de conciliação, emerge o papel de mãe, construído e enraizado historicamente como aquele que somente as mulheres podem exercer e ponto de partida para sua valorização, em nossa sociedade. Nesse cenário, cabe então questionar como se configura a maternidade entrelaçada ao trabalho, isto é, quais questões se apresentam para a mulher, na atualidade, diante do trabalho e da maternidade?

Segundo Fiorin, Oliveira e Dias (2014), poucas são as pesquisas brasileiras dedicadas a entender essa tentativa de conciliação entre o trabalho e a família no que tange à maternidade. Para eles, existem evidências de que há uma relação inversa entre o número de filhos e a dedicação à carreira, de forma que o filho é apresentado como um empecilho à dedicação da mulher a sua vida profissional. Ao mesmo tempo, culturalmente, eles também aparecem como uma experiência única que traz para a mulher uma completa realização. Tal paradoxo é evidenciado pelas mulheres entrevistadas por Fiorin et al. (2014) que apresentam o trabalho como uma atividade remunerada que ultrapassa as necessidades econômicas, na medida em que é fonte de satisfação e prazer, além de trazer a sensação de contribuição com o ambiente laboral e com a sociedade: para elas, o trabalho tem uma importância emocional que proporciona uma sensação de atividade e produtividade.

Desse prisma, a maternidade, social e historicamente idealizada, conectada à potência de vida da mulher e a sua total realização, fica fragilizada, pois figura como uma escolha difícil de ser feita. Nesse sentido, Fiorin et al. (2014) e Marcos (2017) expõem que a vivência da maternidade é complexa e ambígua, por exigir que as mulheres abram mão de seus planos de crescimento pessoal em prol de um exercício da maternidade que responda aos rígidos ideais construídos socialmente.

Na pesquisa de Araújo e Scalon (2006), 79,85\% das entrevistadas, ao serem colocadas diante da afirmação "As crianças sofrem mais se a mãe trabalha fora", respondeu concordando com a frase, o que evidencia a concepção das mulheres de que a dedicação ao trabalho e a seus projetos pessoais pode ser prejudicial ao desenvolvimento de seus filhos e ao exercício de sua função materna. Assim, apresenta-se um conflito entre o trabalho e a maternidade, ou seja, entre o trabalho como valor que garante a independência, a autonomia e a realização pessoal feminina, e a maternidade que é valorizada a partir da presença e do cuidado exclusivo com a prole. Os discursos das mulheres apontam para uma ideia construída ainda no século XIX de que a única capaz de prover o que um filho efetivamente precisa é a mãe.

Outros autores ressaltam mais dificuldades das mulheres nesse binômio trabalho/maternidade. Manente e Rodrigues (2016), ao entrevistarem mulheres buscando compreender suas percepções acerca da gestação e do apoio no ambiente de trabalho, constataram que $90 \%$ das entrevistadas pretendiam retornar às atividades de trabalho, porém, $83 \%$ relataram que esse retorno era um motivo de preocupação relacionada tanto aos imperativos da maternidade quanto às exigências do trabalho e às dificuldades enfrentadas na conciliação dessas duas funções.

Além das ambiguidades e dificuldades atuais, outras questões culturais se evidenciam como pontos que dificultam a relação das mulheres com o trabalho. Rocha-Coutinho (2011) aponta que as mulheres compreendem o trabalho e a maternidade como escolhas pessoais. Para Albertuni e Stengel (2016), são as ideias fortalecidas no século XXI, de que a mulher é livre para escolher e sustentar suas escolhas, que orientam suas reflexões e ações. Assim, as dificuldades, os prazeres, os adiamentos e os investimentos não seriam vistos pelas próprias mulheres como consequências da construção sócio-histórica dos papeis femininos, mas sim como escolhas refletidas e efetivadas por elas mesmas. 
Essa ideia de que as experiências vividas estão ligadas às escolhas pessoais destitui o quanto os interesses políticos, econômicos e sociais influenciam e ressoam sobre os modos de vida que operam em nossa sociedade. Dessa forma, pensar as dificuldades das mulheres diante da articulação trabalho e maternidade não engloba apenas as escolhas pessoais, mas sim questões como: a relação com o parceiro; as experiências e demandas vividas no contexto do trabalho (como pressão, assédio moral, busca por atingir metas etc.); e também aquelas que se apresentam no contexto familiar (como as regras e imperativos de como ser uma boa mãe, a pressão da escola e da dupla ou tripla jornada, a cobrança social e pessoal etc.), de forma que uma infinidade de fatores refletirão na forma como essas mulheres se relacionam com o investimento em suas carreiras, o exercício laboral e a experiência da maternidade.

A partir disso, uma vez que Emídio e Gigek (2019) estudaram a escolha pela não maternidade, um dos movimentos presentes na sociedade atual como já aqui apontado, e trouxeram reflexões importantes sobre a conexão construída socialmente entre femininomaternidade e trabalho; pretende-se, neste estudo, debruçar-se sobre o outro movimento, o de mães que abandonam suas carreiras profissionais para se dedicarem ao cuidado com seus filhos, a partir de uma reflexão sobre maternidade e trabalho. Considerou-se importante compreender esse movimento em sua polissemia e buscar articulá-lo às questões sociais que atravessam a relação da mulher com a maternidade.

\section{Método}

\section{Participantes}

Trata-se de uma pesquisa qualitativa descritiva-explicativa, pois buscou descrever as características de um fenômeno e identificar os fatores que o determinam ou contribuem para sua manifestação. Buscou-se compreender o movimento de mulheres que abandonam suas carreiras para se dedicarem ao cuidado com seus filhos. Para tanto, foram realizadas entrevistas com oito mulheres de classe média, na faixa etária dos 30 aos 50 anos. O número de oito entrevistadas foi considerado suficiente para a análise dos dados em pesquisa qualitativa. Segundo Minayo (2017), não há a necessidade de um número prévio e extenso de entrevistas para explorar os conteúdos pesquisados, logo, o grupo de participantes da pesquisa se configurou a partir da saturação dos conteúdos das entrevistas. A escolha pelo trabalho com mulheres nessa faixa etária oriundas da classe média se relaciona às informações das pesquisas de Rocha-Coutinho $(2007,2011)$ que apontam que esse movimento é mais frequente nessa faixa etária e na classe média brasileira, uma vez que a opção pelo abandono do trabalho se liga também a possibilidades de sustento do grupo familiar sem o salário recebido pela mulher/mãe. As entrevistadas, nomeadas com nome fictícios, são: Gisele, 35 anos, dois filhos, modelo e estilista que abandonou a carreira por conta de inúmeras viagens que não conseguia conciliar com o cuidado dos filhos; Adriana, 38 anos, assistente social que abandonou a carreira para poder passar os períodos matutinos com os filhos; Giovana, 33 anos, publicitária que abandonou a carreira por conta da rotina e falta de horários fixos; Lúcia, 40 anos, engenheira química que não retornou da licença maternidade após o nascimento do primeiro filho; Flora, 35 anos, dois filhos, arquiteta que saiu do emprego após a chegada do segundo filho; Violeta, 38 anos, economista, esperando o terceiro filho, que abandonou a carreira em um banco internacional quando do nascimento do primeiro filho; Manuela, 36 anos, estilista que não retornou da licença maternidade após o nascimento da primeira filha; e Joana, 32 anos, advogada, defensora pública, que havia abandonado o trabalho uma semana antes de ser entrevistada.

\section{Instrumentos e procedimentos}

O instrumento de coleta de dados utilizado foi a entrevista semidirigida. Foi elaborado um roteiro prévio com questões sobre como essas mulheres percebem esse movimento, como foi tomar a decisão e realizar a escolha, como pensam a relação entre o trabalho e a maternidade e quais perspectivas futuras vislumbram a partir dessa tomada de decisão. O contato com as entrevistadas se deu a partir da intermediação de terceiros que as conheciam, de modo que o grupo foi constituído por indicação. A partir do contato com as mulheres, foi agendada uma entrevista no local escolhido por elas. As entrevistas foram gravadas e posteriormente transcritas. A pesquisa foi aprovada pelo Comitê de Ética em Pesquisa da Faculdade de Ciências e Letras de Assis, protocolo CAE no 45472615.0.0000.5401, sendo apresentado às participantes o Termo de Consentimento Livre e Esclarecido antes de cada entrevista. 


\section{Análise dos dados}

A análise dos dados buscou articular o material colhido com o material científico disponível. Pretendeu-se traçar uma interlocução entre o panorama histórico e as transformações do feminino, da maternidade e do trabalho feminino em nossa sociedade, por meio dos relatos das entrevistadas. Segundo Minayo e Guerriero (2014), a análise dos dados em pesquisa qualitativa vai além da mera classificação dos dados obtidos nas entrevistas, pois é preciso efetivar uma escuta atenta dos símbolos que a fala dos entrevistados apresenta e dos códigos sociais que estão contidos nos relatos, valorizando a compreensão dos processos envolvidos e incluindo o que é singular ao se pensar em um contexto histórico e social mais amplo.

Assim, a partir de uma leitura atenta dos relatos das entrevistas, buscou-se identificar os sentidos evidenciados que traziam o caráter de uma contribuição original para o problema de pesquisa. Investigou-se nos relatos dessas mulheres o sentido dessa escolha para os articular às discussões e reflexões teóricas acerca das transformações históricas da maternidade e do papel da mulher na sociedade e sua relação com o trabalho.

Após transcritas, as entrevistas foram lidas de maneira exaustiva para identificar essas marcas e sentidos e, a partir da análise dos conteúdos (Bardin, 2009) que foram salientados pelas entrevistadas, foram construídas três categorias de análise: a) Trabalho e maternidade; b) A maternidade e suas polissemias; e c) Perspectivas futuras: lugares possíveis para a maternagem e o trabalho.

\section{Resultados e discussão}

\section{Trabalho e maternidade}

A partir da análise das entrevistas, pode-se verificar que cada mulher trouxe um olhar diferente sobre a relação estabelecida com o trabalho e com a maternidade, porém, ao mesmo tempo, elas trouxeram conteúdos comuns relacionados aos imperativos sociais, o que evidencia como esses atravessam suas experiências, compondo um modo de se relacionar com o trabalho e a maternidade. A maioria das entrevistadas relataram terem um bom relacionamento com o trabalho e encontrarem satisfação e realização nas atividades desenvolvidas.
As entrevistadas, mulheres de classe média, relataram que a profissão foi escolhida na adolescência e foi idealizada e vivida a partir do ingresso no curso superior e posteriormente no mercado de trabalho, ocupando o lugar em seus imaginários de uma possibilidade de realização pessoal e de conquista de autonomia e independência. A independência e a autonomia apareceram no discurso de todas e elas apontaram que essa era uma conquista feminina que elas valorizavam.

Os discursos das entrevistadas sobre a representação do trabalho coadunam com as ideias de Carreteiro (2011), que aponta que ele tem, para as mulheres, uma representação de conquista de autonomia e de independência, além de ser fonte de realização pessoal e profissional. Nesse sentido, percebe-se que o trabalho faz parte de uma conquista que compõe esse longo caminho de luta pelo empoderamento das mulheres, mas que apresenta-se ainda como um território de instabilidades e de ambivalências para elas.

É importante apontar que essa autonomia e independência não se referem à emancipação coletiva da mulher frente aos imperativos globais da divisão internacional do trabalho (Hirata, 2015), mas exclusivamente à possibilidade de consumir: uma independência financeira, o que poderia libertá-las de um homem provedor, mas não das contradições do mundo do trabalho gentrificado.

Ao falarem sobre o cotidiano de trabalho e sobre como construíram seus espaços e relações nesse contexto, as mulheres comentam o olhar social das carreiras femininas e masculinas, apontaram para as dificuldades de ocupar uma carreira considerada tradicionalmente masculina e pontuaram a necessidade de um posicionamento mais firme nas relações de trabalho, porém, ainda de forma individual. Lúcia coloca:

eu sempre sonhei em ser engenheira e então fui fazer a faculdade, desde lá percebi que precisaria me posicionar, pois embora haja toda essa coisa de trabalho feminino, quando você entra na realidade você percebe que é bem diferente. O trabalho ainda é algo muito ligado ao homem, aquele que traz o dinheiro para a casa e nas indústrias isso é muito presente. Você tem que o tempo todo que provar que é capaz, que entende disso e que podem confiar em você. Isso é desgastante.

O relato de Lúcia se relaciona ao que Hirata (2015) apresenta sobre a divisão sexual do trabalho 
quando aponta que, a despeito das mudanças ocorridas no trabalho, as questões de gênero se apresentam fortemente enraizadas. Maruani (2009) aponta que é no cenário do trabalho que se fortalecem cotidianamente os desníveis de poder entre mulheres e homens, tanto pela determinação de tarefas diferenciadas quanto pela desqualificação, financeira ou simbólica, das tarefas realizadas por mulheres.

O trabalho feminino apresenta ainda na atualidade uma demanda de luta e resistências constantes para que seja aceito, valorizado e reconhecido, o que evidencia também o cenário de desigualdades nas relações de gênero (Hirata, 2018) e o quanto as conquistas e transformações nesse contexto são lentas e graduais, na medida em que devem ser tomadas em sua dimensão coletiva como um problema da classe trabalhadora.

Além desses fatores, as entrevistadas caracterizaram o trabalho como algo que exigia muita dedicação, de forma que sobrava pouco tempo para outras atividades, e expressaram que se sentiam sempre muito cobradas no sentido de oferecer alguma colaboração ao mundo. Segundo elas, toda essa cobrança, com o tempo, impactou em sua vida pessoal e suas relações amorosas e familiares, mesmo antes de terem filhos, conforme Flora e Manuela, que relatarem que antes mesmo de pensarem em ter filhos sentiam-se cobradas com relação ao trabalho e à dedicação à família e que seus parceiros traziam muitas cobranças relacionadas a essa dedicação. Para Gisele, Adriana e Joana, os parceiros foram bastante companheiros diante desses impasses com relação às demandas que se apresentam ao trabalho feminino e à dedicação à família, e buscaram estabelecer com elas um compartilhamento dos cuidados domésticos e com os filhos. Mesmo assim, persistia um sentimento de dívida diante da casa, do cuidado, da dedicação à família e aos filhos. Tudo isso evidencia a centralidade do trabalho na sociedade, mostrando como o sistema produtivo atual e sua organização do trabalho se espraiam pela vida cotidiana, definindo muito mais do que o trabalho produtivo, mas também o trabalho reprodutivo. Nesse sistema, a necessidade da ampliação da capacidade de consumo advinda dos imperativos globais se contrapõe à própria divisão sexual do trabalho, entretanto, permanece vivida no espaço individual e o próprio indivíduo é culpabilizado por sua tragédia de ampliação.

As falas das entrevistadas sobre a culpa, a dívida e a manutenção da vinculação da mulher ao ambiente doméstico se ligam às características construídas quanto à identidade feminina e apontam para o caminho em que, ao longo do tempo, a mulher agregou novas funções e manteve as antigas. Nesse sentido, o cenário atual se apresenta ainda mais complexo diante das demandas para o feminino. Esses sentimentos, segundo as entrevistadas, já estavam presentes antes mesmo de terem filhos e evidenciam que, apesar de a maternidade ter uma centralidade e um peso na construção da identidade da mulher, a característica feminina de responsabilidade pela gestão da família, que remete à representação da mulher burguesa, se mantém fortemente nos dias atuais e leva muitas mulheres a vivenciarem conflitos na tentativa de conciliação desses diversos papeis exercidos pelo feminino.

A fala sobre a cobrança ou não dos parceiros evidencia também a desigualdade de gênero que discutimos anteriormente, seja quanto ao que é trabalho de mulher, seja quanto a seu valor. Pelo conteúdo das entrevistas, demonstra-se a permanência de uma ideia de que deve existir uma divisão de papeis entre o feminino e o masculino. Os parceiros são parte desse processo de abandono das atividades de trabalho, tanto pela cobrança com relação ao papel feminino, quanto pela oferta de apoio para que elas possam "escolher" por permanecer trabalhando ou abandonar suas carreiras.

As entrevistadas relataram que houve uma necessidade de reorganização financeira da família e que esse processo foi bastante angustiante para elas, uma vez que sentiram-se perdendo a autonomia financeira e tornando-se dependentes de seus maridos, o que trouxe uma sensação de perda de uma liberdade conquistada. Ao relatarem sobre a relação de dependência estabelecida com seus parceiros, elas apontam esse fator como de grande peso nos desejos de retornarem ao mercado de trabalho quando os filhos crescerem.

É como se você fosse, ganhasse o mundo, se sentisse livre, mas algo te dissesse que você deveria voltar, esse algo é bom, maravilhoso, seu fruto, seu parceiro, sua família, mas é algo que te prende ao seu parceiro, te faz dependente e isso é bastante pesado, mas ao mesmo tempo, são as prioridades e a possibilidade de viver o que é natural da mulher, né? (Joana)

Nesse sentido, percebe-se que, embora essas mulheres tenham abandonado suas carreiras para se 
dedicarem aos cuidados com os filhos pelo fato de a maternidade ter se apresentado como uma prioridade naquele momento, o trabalho ainda ocupa para elas um lugar de conquistas de autonomia e de reconhecimento social, o que denota a necessidade de se refletir sobre o trabalho feminino e as dificuldades enfrentadas por mulheres na construção de sua carreira.

Mesmo que seja alienado e apresente marcas de uma divisão sexual desigual, o trabalho produtivo ainda ocupa um lugar importante na definição das relações sociais: estar trabalhando ainda remete a autonomia e a liberdade. Isso talvez se deva à incompreensão das pessoas sobre o carácter coletivo do trabalho, ou mesmo à importância do consumo na sociedade, que ofusca a compreensão do papel social, alienando o cidadão (Santos, 1987). Desse modo, pode -se dizer que a mulher, nesse mercado de trabalho altamente alienado, tem sua relação com ele não somente marcada pela passividade diante de suas determinações e dos imperativos sociais, mas há também a possibilidade de ressignificá-lo na realização das práticas cotidianas. (Sato, 2012; Castro, 2020).

\section{A maternidade e suas polissemias}

Ao serem questionadas sobre a maternidade, as entrevistadas responderam da mesma forma: "é uma experiência incrível, maravilhosa". E para elas, ser mãe trouxe uma mudança no olhar para o mundo, para a vida e para as prioridades. As entrevistadas colocaram a maternidade como um divisor de águas em suas vidas e apontaram o abandono de suas carreiras como uma escolha de vida ligada à dedicação aos filhos e a vivência dessa experiência materna. As razões que as levaram a abandono de suas carreiras em prol da maternagem se ligam a fatores diversos. Joana relata:

Ser mãe é uma experiência incrível, e para mim muito biológica. O bebê nasce e você parece uma leoa, pega como se ninguém pudesse dar tudo para ele a não ser você, é algo indescritível, me emociono só de pensar no nascimento dos meus filhos e foi por essa experiência, pela possibilidade de vivê-la de maneira intensa, de curtir cada pedacinho, que eu resolvi abandonar a minha carreira, foi por eles, para termos mais tempo juntos e porque eu acredito que eles serão também mais felizes e mais seguros assim.
A fala de Joana se articula ao que Badinter (2010) explica sobre uma tendência naturalista que tem sido retomada em nossa sociedade e que vincula a maternidade a um potencial biológico da mulher, devido ao qual as mulheres estariam fadadas a gerar, a amamentar e a viver essa experiência como algo imprescindível para a vida do filho. $\mathrm{O}$ relato de Joana se liga às construções sociais e às teorias do desenvolvimento segundo as quais a mãe é a figura central na vida do filho e a única que pode oferecer o que ele precisa. Para ela, esse vínculo possibilita que as pessoas cresçam mais maduras e seguras, como discutido por Kalil e Aguiar (2016). Tais acepções constituem uma nova/velha roupagem para a maternidade na atualidade, pois é cobrada das mães a responsabilidade pelo desenvolvimento de seus filhos, vinculado a uma disponibilidade biológica para tal função. Essa fundamentação mais naturalista apresenta-se como um imperativo que busca que as mulheres fortaleçam antigos papéis e reforcem experiências valorizadas em tempos anteriores, levando-as a abandonarem conquistas relacionadas a uma reflexão sobre a experiência da maternidade e a assumirem esta como uma obrigação inata da mulher.

Ao serem questionadas sobre a articulação entre trabalho e maternidade, as entrevistadas apresentaram que são dois campos de conflito. Adriana relata:

é uma conciliação que para mim foi incompativel. É como se você não exercesse nem uma, nem a outra função direito, é muita cobrança. Eu sentia que não respondia às demandas do meu trabalho, aquilo me angustiava. Eu tentei conciliar, mas por conta de me sentir extremamente sobrecarregada eu optei por investir somente na maternidade, achei que traria mais benefícios em casa. Além disso, na nossa sociedade tudo recai muito sobre a mulher, então eu vivia devendo horas no meu trabalho porque meu filho ficava doente, às vezes precisava sair mais cedo, porque o mundo do trabalho não está preparado para as demandas de uma mãe, ele as expulsa de lá, como se não tivéssemos mais valor e foi pensando em tudo isso que resolvi sair.

A fala de Adriana se relaciona a muitos impasses apresentados nas discussões de Rocha-Coutinho (2007), Sousa e Guedes (2016), Hirata e Kergoat (2007) e Hirata $(2014,2018)$ que defendem que a divisão sexual do trabalho é algo que modula e sustenta a 
relação entre homens e mulheres e que, consequentemente, o ingresso destas no contexto do trabalho não trouxe um equilíbrio entre as funções exercidas pelas mulheres, mas sim reforçou as desvantagens vividas por elas. Ao agregarem o papel de mulher trabalhadora, viram-se diante de uma tentativa de conciliação de demandas apresentadas pelos dois espaços: o laboral e o familiar. Considerando a compreensão parcial do trabalho apontada anteriormente, a fala das entrevistadas e o empobrecimento da compreensão de maternidade imputado pelo biologicismo referido acima, pode-se dizer que conciliar trabalho e maternidade dificilmente vai resultar em algo que não seja sofrimento para a mulher e dificuldade em acreditar que ambos são conciliáveis. No caso desta pesquisa, as entrevistadas escolheram pela dedicação exclusiva à maternidade, porém, a palavra escolha tem um peso relativo em seus relatos, uma vez que considerar que elas de fato escolheram pode ser um equívoco, quando pensamos na situação vivenciada pelas mulheres e na complexidade dos imperativos que atravessam essa ação.

Diante de um contexto de trabalho desigual, de conquistas que não se efetivam e de um cenário de trabalho onde não há uma adaptação à experiência de maternagem de mulheres trabalhadoras, dizer que elas escolhem entre uma e outra função é considerar que em algum momento da história o desejo da mulher foi efetivamente considerado, o que talvez, mesmo no século XXI, seja um ledo engano. Às mulheres é possível escolher, desde que suas escolhas atendam aos imperativos sociais e às demandas do capitalismo, do Estado e da família. Evidencia-se, assim, um controle permanente sobre a mulher, que, diante de um longo processo de transformação em nossa sociedade, se manifesta velado, com vestes de leveza, mas que traz um peso expressivo diante dessas experiências e um olhar da sociedade que continua a desvalorizá-las.

A desvalorização emergiu nas respostas das mulheres sobre como o meio social e familiar percebeu a escolha pelo abandono da carreira em prol da dedicação ao cuidado com os filhos. Flora explica que ainda hoje falar sobre o pedido de demissão e o retorno ao lar causa estranhamento nas pessoas:

As pessoas não acreditam que fui capaz disso, quando falo se espantam, mas o mais impressionante é que não valorizam. Certa vez uma mulher me disse: e você então não faz nada o dia todo. Aquilo me impactou demais, pois no meu dia não sobrava um segundo de calmaria e sossego, passava o dia envolvida com atividades de casa e das crianças, mas porque não estava ligada a um trabalho formal, remunerado e reconhecido socialmente o olhar das pessoas era de estranhamento. (Flora)

Violeta também comenta essa questão:

Eu estava numa posição de muito destaque no meu trabalho quando engravidei, e já na gestação sentia muita dificuldade em lidar com isso, parecia que minha gestação atrapalharia o meu trabalho, que sair de licença interromperia um ciclo de produção meu e isso me incomodava, eu pensava, poxa eu estou tento a capacidade de gerar uma vida e estou pensando na minha produção, no que vou dar para o banco?

A impossibilidade de compreender o trabalho e sua determinação segundo um sistema produtivo que atua francamente sobre o processo de subjetivação, acarretam a autoculpabilização da vítima. Dessa forma, os relatos de Flora e Violeta apontam para as contradições desse cenário e as incompatibilidades diante de imperativos tão perversos que se constituem em relação à mulher. Ao mesmo tempo que devem ser boas mães e se dedicar ao cuidado com os filhos, elas devem dar conta das demandas do trabalho e assim serem valorizadas e reconhecidas. A sociedade espera que as mulheres respondam positivamente a todos os seus papéis e, como aponta Badinter (2010), constrói parâmetros aos quais essa mulher deve se enquadrar, de forma que qualquer movimento que se afaste disso causa estranhamento no outro e gera uma busca por reenquadrar a mulher nesses papeis socialmente construídos.

Ao falar sobre como os outros olham para sua decisão, Manuela, que ocupava um lugar de destaque no mundo da moda, diz que as pessoas ligavam para saber qual a estratégia ela estava usando e não acreditavam que ela havia abandonado o trabalho. Ela diz que enxerga esse movimento de mães que retornam ao contexto doméstico como uma revolta, uma resposta a um contexto de trabalho que não acolheu a mulher.

Eu nem voltei da licença maternidade porque me senti muito invadida nesse período, me ligavam 
da firma e eu me sentia desrespeitada, estava vivendo o momento mais especial da minha vida e era como se o trabalho fosse um segundo bebê me chamando, me revoltei e disse ao meu marido, para esse lugar eu não volto, me revoltei, vou ficar em casa, cuidar das crianças, vou resistir a essa loucura, não quero mais, me vestir de "mulherzinha" e fiquei em casa, porque desacreditei no que se oferece à mãe trabalhadora.

$\mathrm{O}$ relato de Manuela aponta para uma faceta antes não discutida ao pensar esse movimento das mulheres de volta para casa, o da resistência. Os trabalhos de Rocha-Coutinho $(2007,2011)$ apontam que esse movimento, possível de se estruturar na classe média brasileira, se liga às dificuldades de conciliação entre as demandas do trabalho e da maternidade, fatores que também se apresentaram no discurso das entrevistadas deste trabalho. Contudo, a partir das leituras das entrevistas, percebeu-se que essas mulheres, quando tomam a decisão de não voltar ao mercado, se ligam a uma (re)volta no duplo sentido do termo: a revolta do retorno, da segunda vez, em que a mulher volta ao contexto doméstico atravessada pelo discurso naturalista e por uma tentativa de retomada da valorização da relação mãe e filho e dos cuidados ofertados por esta; e a revolta no sentido de se rebelar contra o sistema, contra o modo produtivista em que está inserida e contra a falta de condições específicas para o acolhimento da mãe trabalhadora: é uma revolta resultante de uma compreensão individualizada dos problemas do trabalho, pois, no caso das nossas entrevistadas, esta revolta não suscitou o engajamento com entidades representativas da luta feminina por melhores condições de trabalho e de vida.

Nesse sentido, ao serem questionadas se o abandono de suas carreiras poderia ser associado à relação que elas construíram com suas mães, pode-se perceber que muitas delas colocam que a retomada dessa experiência foi de grande importância nas ponderações e reflexões no processo de tomada de decisão. Gisele relata:

Eu tive uma mãe muito empoderada, minha mãe foi juíza, não tinha muito tempo, sofria por não ficar com a gente, mas a prioridade dela era nos oferecer uma educação de qualidade e todo o conforto do mundo, olhar para a nossa relação tão distante e para todo o valor que ela sempre deu ao trabalho, foi algo que sustentou o meu desejo por voltar para casa, eu não queria isso para mim, para minha mãe isso é coisa de mulherzinha, para mim é uma questão de prioridades.

Joana, ao contrário de Gisele, expressa que sua mãe foi uma mãe bastante dedicada, que nunca trabalhou fora e que, ao olhar para a mãe que teve, sentia-se impotente diante do que estava oferecendo a seus filhos, motivo pelo qual o retorno ao modelo de maternagem oferecido a ela foi de extrema importância em seu processo de decisão.

Considerando que essas mulheres, em sua maioria, foram filhas de uma primeira ou segunda geração de mulheres que conquistaram possibilidades de ingresso no mercado de trabalho, é importante refletir sobre as ressonâncias dessas experiências na construção da identidade feminina das filhas. Nos discursos de Joana e Gisele há um ponto em comum: o fato de o trabalho ser visto pelas duas como algo que rouba a possibilidade de ter, ou de ser, uma mãe dedicada às exigências da maternidade. Para Gisele, sua mãe empoderada não pode ser uma mãe próxima e para Joana o fato de sua mãe não trabalhar fora de casa possibilitou que esta pudesse se dedicar a ela e às irmãs. Nesse sentido, percebe-se que entre o trabalho e a maternagem há uma polaridade construída socialmente em que um rouba do outro aquilo que tem de potência, como algo a oferecer.

Nessa lógica, as mães trabalhadoras são vistas como aquelas que não podem ofertar uma boa maternagem, sentidas como ausentes, autocentradas e distantes; já as mães dedicadas ao contexto da casa não podem ser mulheres empoderadas, pois não podem exercer um trabalho produtivo e de reconhecimento social. Essa dicotomia se evidencia no discurso de todas as entrevistadas, seja pela identificação com suas mães dedicadas à maternagem, seja por oposição àquelas mães que construíram uma carreira profissional. Parece não ser permitido, pelo que se construiu no imaginário social sobre a mulher e a mãe, que elas exerçam essas múltiplas funções. Assim, novas contradições aparecem: ao mesmo tempo que se cobra que as mulheres acumulem papéis e funções, considera-se isso como algo impossível de ser atingido.

Porém, no meio desses atravessamentos está a mulher, sua história e suas lutas em um processo de construção de identidade contraditório, conflituoso, lento e gradual. Luta-se muito, constrói-se pouco, 
mas vislumbra-se sempre uma possibilidade de resistir. Instituem-se movimentos, há aquelas que desejam não ter filhos, há aquelas que abandonam o trabalho, há aquelas que resistem em uma tentativa constante de conciliação, mas ainda há luta e resistência, ressonâncias também do que as mulheres ao longo da história puderam construir.

\section{Perspectivas futuras: lugares possíveis para a maternagem e o trabalho}

Ao serem questionadas sobre as perspectivas futuras, todas as mulheres, com a exceção de Joana, relataram que tinham como objetivo retornar ao trabalho e apontaram a presença do medo com relação ao futuro. Isso se relaciona tanto ao medo de cobrarem dos filhos e da família, como ao de se sentirem inúteis e improdutivas conforme os filhos cresçam. A partir disso, perguntou-se para as mulheres o que mais sentiam falta na experiência com o trabalho e todas prontamente responderam que era da autonomia, da independência financeira e do contato social que $o$ trabalho promove. As entrevistadas expressaram que a maternidade, apesar de ser uma experiência de grande intensidade, é também muito solitária e que sentiam falta da socialização promovida pelo trabalho.

No relato das entrevistadas, evidenciou-se que a relação entre o trabalho e a maternidade na atualidade apresenta para as mulheres uma amplitude de questões e reflete valores enraizados socialmente tanto com relação ao trabalho feminino quanto com relação à maternidade. Nesse sentido, elas se veem sozinhas e despotencializadas diante das ambivalências que experienciam.

O desejo de retomar ao trabalho que essas mulheres trazem em seus discursos apontam para uma questão bastante discutida por Antunes (1995) e Alves (2000) acerca da centralidade do trabalho na vida moderna e apontada por Aguiar, Jesus, Bastos e Lago (2014), ao discutirem sobre os conflitos na relação trabalho-família, que situam o trabalho como a única via para responder às demandas da sociedade $\mathrm{e}$ para a mulher sentir-se inserida.

Ao escutar essas mulheres, percebe-se que, embora a maternidade seja uma experiência bastante valorizada, para elas o reconhecimento social da mulher só é alcançado pela via do trabalho, por mais contraditório que isso possa parecer, já que ele não as acolhe, apresenta condições precárias e as expulsa de volta para casa. Assim, ele é desejado como cenário de socialização, de autonomia e de independência financeira, bem como fonte de autorreconhecimento e reconhecimento social, que foi perdido com a decisão de se dedicarem integralmente ao cuidado com os filhos.

Porém, essa relação da mulher com o trabalho não é decidida por elas, a partir de seus próprios desejos, mas sim ligada a todo um sistema, a todo um engendramento que coloca a mulher como aquela que atende às demandas sociais de cada período. Esse sistema não as permite uma escolha individual e desengajada dos desafios que se impõem às mulheres como integrantes de uma classe-que-vive-do-trabalho (Antunes, 1995), para atender aos imperativos de retorno ao lar motivado por um imperativo biológico, naturalista de maternidade, pois imputa à própria mulher trabalhadora a culpa da ação e as inseguranças com relação às perspectivas futuras.

Essas questões apontam para um debate importante sobre um cenário de trabalho que não respeita a mulher, mãe e trabalhadora, imputando-lhe culpa por suas dificuldades e afirmando que ela deve tolerar sua condição precária ou sair, como fizeram as entrevistadas desta pesquisa. Desse modo, de acordo com Hirata (2015), essas mulheres estão inseridas em um contexto de um mercado de trabalho que impõe padrões duros, às vezes inalcançáveis e insuportáveis, o que as leva ou a viverem sob o dilema da negociação, da culpa, da busca por superação e por oferecer cada vez mais, ou a adoecerem no trabalho, ou ainda a saírem do mercado e viverem a experiência do abandono da carreira em prol da dedicação integral à maternidade.

$\mathrm{Na}$ fala das mulheres entrevistadas, não se observa uma reflexão acerca de seu papel social e sua condição enquanto mulher trabalhadora relacionada às demandas do mercado e aos imperativos sociais. As mulheres apresentam em suas falas um discurso de culpa e retratam a questão de estar ou não no mercado de trabalho como uma escolha delas, como algo que depende delas e que elas não conseguiram conciliar com as demandas da maternidade e com o ideal de maternidade que queriam exercer. Nesse sentido, evidencia-se uma condição em que a mulher é capturada por esses discursos e sofre diante das demandas apresentadas, além de acreditar que decorre dela mesma a impossibilidade de conciliação entre maternidade e trabalho, como se sua construção enquanto mulher, sujeito e cidadã fosse algo singular e não atravessado pela pluralidade de um sujeito 
social, coletivo, constituído em uma historicidade. Os imperativos sociais e a lógica perversa do mercado de trabalho com as mulheres, exigem que elas se apresentem inteira e completamente disponíveis para ele, sob a pecha de serem excluídas do mercado ou não sustentarem seus postos de trabalho. Desse modo, de acordo com Marques (2016), pode-se pensar que historicamente, no Brasil, os direitos trabalhistas femininos se mostram frágeis e inflexíveis, por não considerarem o trabalho da mulher e não oferecerem segurança para seu exercício.

Assim, percebe-se a lógica do modelo de trabalho que imputa ao trabalhador a "responsabilidade" por sua experiência com o trabalho, bem como com as metas e os objetivos traçados, sem considerar as contingências da vida, as diversidades que se apresentam e as demandas relacionadas ao trabalho feminino e à maternidade, o que faz da mulher mais uma peça de uma engrenagem em que a dimensão humana do trabalho se esvazia. É um sistema cruel que insere as mulheres como mão de obra necessária sem rediscutir a divisão sexual do trabalho ou a maternidade. Nesse sentido, há uma sobrecarga sobre as mulheres, que se deparam com exigências tanto do trabalho produtivo quanto do trabalho reprodutivo (Meyer, Oliveira, Coelho, \& Aquino, 2019) e se esforçam para manter um ritmo de produtividade, o que configura uma sobrecarga e leva ao sofrimento psíquico e aos sentimentos de desamparo e solidão.

Um outro fator que se apresenta nos relatos é que apesar de desejarem retornar ao mercado de trabalho, as mulheres entrevistadas dizem não se arrepender da escolha que fizeram. Sentem que estão dando o seu melhor na função que escolheram exercer, mas também sentem medo e receio do futuro. Além disso, apresentam o desejo de empreender, de construir um negócio próprio, por buscarem um trabalho mais autônomo. Quando questionadas acerca do porquê de ter um negócio próprio, as entrevistadas apontaram que mesmo crescidos, os filhos vão apresentar demandas a elas, e um negócio de que elas sejam chefes facilitaria a disponibilidade de horários, a organização da agenda e a conciliação com as demandas familiares, o que demonstra que, embora haja um desejo de retorno ao mercado de trabalho, ele ainda permanece atravessado pelo desejo de manter uma dedicação à maternidade dentro dos padrões exigidos.

Meyer et al. (2019, p. 51) ao discutirem a questão do empreendedorismo feminino e sua relação com as demandas domésticas, defendem que essa busca por empreender em casa resulta da precariedade em que se deu a inserção feminina no mercado de trabalho e que permanece na atualidade, fazendo com que mulheres, na busca por reconhecimento e complementação de renda, partam em busca de montar um negócio próprio, em casa, que acaba intensificando sua atividade laboral de forma "progressiva e invisível". Nesse sentido, é como se houvesse um exercício constante das mulheres em busca de romper essa lógica dos imperativos sociais que vinculam a maternidade a um impedimento do trabalho, como se filhos e trabalho não pudessem compor uma experiência de vida feminina, em uma luta constante para que a mulher possa afirmar seu papel social e suas relações e possivelmente constituir escolhas. Como se elas tivessem que provar que é possível ser mãe trabalhadora sem que haja qualquer transformação no cenário do trabalho e no doméstico, como se o exercício de adaptação e de superação fosse algo apenas da ordem do feminino, segundo os padrões sociais aparentemente inquestionáveis.

Além disso, o discurso das entrevistadas aponta para a relação estabelecida entre o mercado de trabalho e a mulher, em que esta não se sente acolhida com relação às especificidades das funções sociais que exerce. Ela precisa "escolher" ou buscar alternativas que nem sempre são possíveis para se colocar em dois lugares onde sua função social se construiu: no lugar da mãe e no da mulher trabalhadora.

\section{Considerações finais}

As análises e críticas empreendidas até o momento não podem ser compreendidas simplesmente olhando para a precarização do trabalho e a sustentação de uma maternidade naturalmente exclusivista. Nem um nem outro são elementos estanques que podem ser unidos ou separados para o exercício de análise desse fenômeno.

Fica claro na fala das entrevistadas a carência de uma compreensão maior sobre a natureza social do trabalho e as consequências de se apostar, enquanto sociedade, em um desenvolvimento neoliberal, altamente competitivo e individualista. Isso se evidencia ainda mais quando apontam para o empreendedorismo como uma saída para a conciliação entre a maternidade e o trabalho. A flexibilidade de horários, a inexistência de um chefe e, por vezes, a falta de necessidade de sair de casa para trabalhar não 
garantem a ausência de exploração e de uma realidade pouco acolhedora de trabalho: basta considerar para as dificuldades vividas por tantos motoristas ou trabalhadores por aplicativo. Tanto o trabalho quanto a maternidade precisam ser repensados e discutidos anteriormente, ou seja, quando os cidadãos decidem os rumos da sociedade, fatalmente pautados na escolha do sistema produtivo. Trata-se de um posicionamento político que está nas bases da vida cotidiana e que sustenta o engajamento com a vida de todos.

Para finalizar as reflexões acerca da interface trabalho e maternidade, em busca de compreender o movimento de mães que abandonam o mercado de trabalho para se dedicarem ao cuidado com os filhos, encontrou-se no relato de Lúcia uma fala que representa as diversas facetas dessa relação. Lúcia relata: "é como se eu estivesse vivendo uma suspensão do trabalho. Como se fosse uma suspensão para me dedicar aos meus filhos e depois retomar o investimento em questões de realização externas à minha família".

O relato de Lúcia e a reflexão acerca dos discursos das mulheres entrevistadas suscitam alguns questionamentos com relação ao lugar da maternidade quando se pensa no trabalho da mulher. As mulheres entrevistadas trazem em seus discursos o desejo de retomar o investimento no trabalho, bem como o desejo de um trabalho que compreenda os papéis que agrega e que as possibilite vivenciar as conquistas e o reconhecimento que no imaginário social o trabalho pode oferecer.

Nesse cenário, pode-se considerar que o exercício da maternidade, enquanto dedicação integral da mulher, é um papel ligado ao desejo de se obter o reconhecimento de sua função de mãe enraizada como um valor pessoal e social que compõe os caminhos da vida de uma mulher. Porém, essa sublime maternidade aparece também como um tempo de suspensão, um tempo em que a mulher abre mão de um investimento em questões individuais e profissionais em prol do investimento em sua relação com o filho e com o grupo familiar. Dessa forma, a maternidade apresenta-se como um sacrifício dos desejos femininos em função de um "bem maior", que é a educação e o cuidado com as crianças, e evidencia o lugar e o valor da mulher na divisão sexual do trabalho.

Essa maternidade-suspensão pode ser pensada por diversos prismas: pode ser vista como obstáculo, algo que atrapalha os caminhos de investimentos femininos, que as priva de autonomia e da possibilidade de conquistas individuais, as aprisionando nessa função; pode ser vista como um investimento temporário, uma suspensão de um investimento na carreira e no mercado para um cuidado com os filhos e com a família que também traz satisfação. Mas sobretudo evidencia a dificuldade das entrevistadas de vislumbrar alternativas de conciliação entre o trabalho e a maternidade.

Dessa forma, é possível olhar para o movimento dessas mulheres a partir de ambivalências e polivalências. A experiência entre o trabalho e a maternidade pode ser pensada pela ótica da renúncia, uma renúncia ligada aos imperativos sociais e às exigências com relação à mulher agregadas ao longo dos anos, uma renúncia que as faz escolher e as imputa a culpa, o medo e as inseguranças, e as conecta precariamente ao prazer social e até mesmo "naturalista" do cuidado com a prole.

O movimento também pode ser olhado pela ótica da (re)volta, a volta no sentido do retorno ao lugar primeiramente valorizado para a mulher, o lugar materno, mas também a (re)volta no sentido de revoltar-se, de um posicionamento de resistência diante dos imperativos sociais e das demandas com relação a sua função social. É uma revolta diante do cenário do trabalho que ao mesmo tempo que as chama e que aparece como algo que as valoriza e promove seu reconhecimento, não as acolhe, não se atenta também às especificidades de suas demandas, que as expulsam construindo um ciclo entre avanços e recuos, no árduo processo de construção do lugar social da mulher, um processo repleto de ambivalências, de caminhos e descaminhos, de voltas e (re)voltas.

Essas questões apontam para a necessidade de escuta desse sofrimento feminino que levou à configuração de movimentos opostos entre não querer ter filhos ou se dedicar integralmente ao cuidado deles, evidenciando os imperativos contraditórios que as atravessam e a necessidade que essas questões sejam debatidas e revisitadas pensando as especificidades do trabalho exercido pela mulher-mãe em busca de construir cenários onde possa efetivamente ter liberdade de escolhas e de posicionamentos diante dos imperativos que se apresentam. A sociedade precisa rediscutir a importância do trabalho reprodutivo, bem como a divisão sexual do trabalho, que, mesmo remontando à ancestralidade, não é natural e sim social, assim como a maternidade. 


\section{Referências}

Aguiar, C. V. N., Bastos, A. V. B., Jesus, E. S. de, \& Lago, L. N. A. (2014). Um estudo das relações entre conflito trabalho-família, comprometimento organizacional e entrincheiramento organizacional. Revista Psicologia Organizações e Trabalho, 14(3), 283-291. http://pepsic.bvsalud.org/scielo.php?script=sci_arttext\&pid=S1984$66572014000300004 \& \operatorname{lng}=\mathrm{pt} \& \operatorname{lng}=\mathrm{pt}$

Albertuni, P. S., \& Stengel, M. (2016). Maternidade e novos modos de vida para a mulher contemporânea. Psicologia em Revista, 22(3), 709-728.

Alves, G. (2000). O novo e precário mundo do trabalho. Boitempo.

Antunes, R. (1995). Adeus ao trabalho? Ensaio sobre as metamorfoses e a centralidade do mundo do trabalho. Cortez.

Araújo, C., \& Scalon, C. (2006). Gênero e a distância entre a intenção e o gesto. Revista Brasileira de Ciências Sociais, 21(62), 45-68. https://doi.org/10.1590/S0102-69092006000300003

Badinter, E. (2010). O conflito: a mulher e a mãe. Record.

Barbosa, P. Z., \& Rocha-Coutinho, M. L. (2012). Ser mulher hoje: a visão de mulheres que não desejam ter filhos. Psicologia \& Sociedade, 24(3), 577-587. https://doi.org/10.1590/S0102-71822012000300011

Bardin, L. (2009). Análise de Conteúdo. Edições 70.

Bruschini, M. C. A. (2007). Trabalho e gênero no Brasil nos últimos dez anos. Cadernos de Pesquisa, 37(132), 537-572. https://doi.org/10.1590/S0100-15742007000300003

Carreteiro, T. C. (2011). História de vida laboral familiar em duas gerações: trabalho e contextos sociais. In T. FéresCarneiro (Org.), Casal e Família: Conjugalidade, parentalidade e psicoterapia (pp. 119-132). Casa do Psicólogo.

Castro, M. F. (2020). Os motoboys de São Paulo e a produção de táticas e estratégias na realização das práticas cotidianas. FiloCzar.

Emídio,T.S.,\&Gigek,T. (2019). “Elasnãoqueremsermães”: algumasreflexõessobrea escolhapelanão maternidadena atualidade. Trivium: Estudos Interdisciplinares, 11(2), 186-197. https://doi.org/10.18379/2176-4891.2019v2p.186

Fiorin, P. C., Oliveira, C. T., \& Dias, A. C. G. (2014). Percepções de mulheres sobre a relação entre trabalho e maternidade. Revista Brasileira de Orientação Profissional, 15(1), 25-35. http://pepsic.bvsalud.org/scielo. php?script=sci_arttext\&pid=S1679-33902014000100005\&lng=pt\&tlng=pt

Guedes, M. C., \& Araújo, C. (2011). Desigualdades de gênero, família e trabalho: mudanças e permanências no cenário brasileiro. Revista Gênero, 12(1), 61-79.

Hirata, H. (2014). Gênero, classe e raça Interseccionalidade e consubstancialidade das relações sociais. Tempo Social, 26(1), 61-73.

Hirata, H. (2015). Mudanças e permanências nas desigualdades de gênero: divisão sexual do trabalho numa perspectiva comparada. Friedrich Ebert Stiftung Brasil, 7.

Hirata, H. (2018). Gênero, Patriarcado, Trabalho e Classe. Trabalho necessário, 16(29), 14-26. https://doi.org/ 10.22409/tn.16i29.p4552

Hirata, H., \& Kergoat, D. (2007). Novas configurações da divisão sexual do trabalho. Cadernos de Pesquisa, 37(132), 595-609. https://dx.doi.org/10.1590/S0100-15742007000300005

Instituto Brasileiro de Geografia e Estatística. (2012). Censo Demográfico 2010. Famílias e domicílios. Resultados da amostra. http://www.censo2010.ibge.gov.br

Kalil, I.R., \&Aguiar,A.C. (2016).Trabalho feminino, políticas familiares ediscursos pró-aleitamento materno: avanços e desafios à equidade de gênero. Saúde em Debate, 40(110),208-223. https://doi.org/10.1590/0103-1104201611016

Losada, B. L., \& Rocha-Coutinho, M. L. (2007). Redefinindo o significado da atividade profissional para as mulheres: O caso das pequenas empresárias. Psicologia em Estudo, 12(3), 493-502. https://doi.org/10.1590/ S1413-73722007000300006

Manente, M. V., \& Rodrigues, O. M. P. R. (2016). Maternidade e Trabalho: Associação entre depressão pós-parto, apoio social e satisfação conjugal. Pensando familias, 20(1), 99-111. http://pepsic.bvsalud.org/ scielo.php?script=sci_arttext\&pid=S1679-494X2016000100008\&lng=pt\&tlng=pt

Mansur, L. H. B. (2003). Sem filhos: A mulher singular no plural. Casa do Psicólogo.

Marcos, C. M. (2017). O desejo de ter um filho e a mulher hoje. Trivium - Estudos Interdisciplinares, 9(2), 246-256. https://doi.org/10.18379/2176-4891.2017v2p.246 
Marques, T. C. N. (2016). A regulamentação do trabalho feminino em um sistema político masculino- Brasil: 1932-1943. Estudos Históricos, 29(59), 667-686.

Maruani M. (2009). Emprego. In H. Hirata, F. Laborie \& D. Senetier (Orgs.), Dicionário crítico do Feminismo (pp. 85-90). Editora Unesp.

Minayo, M. C. S. (2017). Amostragem e Saturação em Pesquisa Qualitativa: consensos e controvérsias. Revista Pesquisa Qualitativa, 5(7), 01-12. https://editora.sepq.org.br/rpq/article/view/82

Minayo, M. C. S., \& Guerriero, I. C. Z. (2014). Reflexividade como éthos da pesquisa qualitativa. Ciência \& Saúde Coletiva, 19(4), 1103-1112. https://doi.org/10.1590/1413-81232014194.18912013

Meyer, D. E. E. (2006). Uma politização contemporânea da maternidade: construindo um argumento. Gênero, 6(1), 81-104. https://periodicos.uff.br/revistagenero/article/view/31010

Meyer, A. V. T. L., Oliveira, E. N. P., Coelho, R. N., \& Aquino, C. A. B. (2019). Trabalho doméstico e empreendedorismo: a intensificação laboral das donas-de-casa. Revista Laborativa, 8(2), 36-56. https://ojs.unesp.br/ index.php/rlaborativa/article/view/2882

Rocha-Coutinho, M. L. (2007). Família e emprego: conflitos e expectativas de mulheres executivas e de mulheres com um trabalho. In T. Féres-Carneiro (Org.), Família e Casal: Saúde, trabalho e modos de vinculação (pp. 203-228). Casa do Psicólogo.

Rocha-Coutinho, M. L. (2011). De volta ao lar: mulheres que abandonaram uma carreira profissional bem sucedida com o nascimento dos filhos. In T. Féres-Carneiro (Org.), Casal e Família: Conjugalidade, parentalidade e psicoterapia (pp. 143-148). Casa do Psicólogo.

Santos, M. (1987). O espaço do cidadão. Nobel.

Sato, L. (2012). Feira livre: organização, trabalho e sociabilidade. Edusp.

Sousa, L. P., \& Guedes, D. R. (2016). A desigual divisão sexual do trabalho: um olhar sobre a última década. Estudos Avançados, 30(87), 123-139. https://doi.org/10.1590/S0103-40142016.30870008

\section{Thassia Souza Emidio}

Professora Assistente Doutora do departamento de Psicologia Clínica e do Programa de Pós-graduação em Psicologia da Faculdade de Ciências e Letras de Assis da Universidade Estadual Paulista Júlio de Mesquita Filho (Unesp), Assis - SP. Brasil. Coordenadora do Laboratório de Estudos e Pesquisas em Psicanálise e Vincularidade (LapsiVi) e vice-líder do grupo de pesquisa (CNPq) com o mesmo nome. Doutora, mestre e graduada (Bacharelado, Licenciatura e Formação de Psicólogo) em Psicologia pela Universidade Estadual Paulista Júlio de Mesquita Filho (Unesp), Assis - SP. Brasil. É membro do grupo de pesquisa Figuras e Modos de Subjetivação no Contemporâneo e da Red Latinoamericana de Estudios Sociales en Parentalidades (RLAESP), Chile. Tem experiência na área de Psicologia Clínica. Desenvolve pesquisas com ênfase em maternidade, feminino, psicanálise vincular e psicoterapia familiar, atuando principalmente nos seguintes temas: família, vincularidade, maternidade e parentalidade.

E-mail: thassia.emidio@unesp.br

(1) https://orcid.org/0000-0002-4353-0912

\section{Matheus Fernandes de Castro}

Professor Assistente Doutor do Departamento de Psicologia Social e do Programa de Pós- graduação em Psicologia da Faculdade de Ciências e Letras de Assis da Universidade Estadual Paulista Júlio de Mesquita Filho (Unesp), Assis - SP. Brasil. Coordenador do Laboratório de Psicologia Ambiental (LAPA-PET). Doutor em Psicologia Social e do Trabalho pela Universidade de São Paulo (USP), São Paulo - SP. Brasil. Mestre em Psicologia e Sociedade pela Universidade Estadual Paulista Júlio de Mesquita Filho (Unesp), Assis-SP. Brasil. É membro do grupo de pesquisa Figuras e Modos de Subjetivação no Contemporâneo e do grupo Trabalho e Processos Organizativos na Contemporaneidade (ANPEPP). Tem experiência na área de Psicologia, com ênfase na área Social, do Trabalho e Ambiental, atuando principalmente nos seguintes temas: trabalho e cotidiano, trabalho e ambientes virtuais, saúde do trabalhador, cooperativismo e economia solidária, espaço, cidades, motoboy, mototaxi, mundo do trabalho e psicodinâmica do trabalho.

E-mail:mf.castro@unesp.br

(1) https://orcid.org/0000-0002-6554-7846 
Endereço para envio de correspondência:

Universidade Estadual Paulista. Faculdade de Ciências e Letras de Assis. Departamento de Psicologia Clínica/

Departamento de Psicologia Social. Av. Dom Antônio, 2100, Parque Universitário. CEP: 19806-900. Assis - SP. Brasil.

Recebido 25/03/2019

Aceito 25/05/2021

Received 03/25/2019

Approved 05/25/2021

Recibido 25/03/2019

Aceptado 25/05/2021

Como citar: Emidio, T. S., \& Castro, M. F. de. (2021). Entre Voltas e (Re)voltas: um Estudo sobre Mães que abandonam a Carreira Profissional. Psicologia: Ciência e Profissão, 41, 1-16. https://doi.org/10.1590/1982-3703003221744

How to cite: Emidio, T. S., \& Castro, M. F. de. (2021). Between Shifts And Uprisings: a Study on Mothers who abandon their Professional Careers. Psicologia: Ciência e Profissão, 41, 1-16. https://doi.org/10.1590/1982-3703003221744

Cómo citar: Emidio, T. S., \& Castro, M. F. de. (2021). Entre Vueltas y (Re)vueltas: un Estudio sobre Madres que renuncian a su Carrera Profesional. Psicologia: Ciência e Profissão, 41, 1-16. https://doi.org/10.1590/1982-3703003221744 